\title{
Kinetics Study of Imidazole-Cured Epoxy-Phenol Resins
}

\author{
YI-CHENG CHEN, WEN-YEN CHIU, KING-FU LIN \\ Department of Chemical Engineering, National Taiwan University, Taipei, 10617, Taiwan
}

Received 16 December 1998; accepted 29 March 1999

\begin{abstract}
The reaction kinetics of diglycidyl ether of bisphenol A (DGEBA) cured with different concentrations of imidazole and bisphenol A (BPA) were investigated by using differential scanning calorimetry. Both dynamic and isothermal DSC were studied. Two initiation mechanisms were found to play roles in the curing reactions. One was based on adduct formation of epoxy groups with pyridine-type nitrogen and the other was based on ionic complexes of imidazole and BPA. The subsequent propagation was composed of three main reactions, viz. the epoxide/phenol reaction, the acid/base reaction, and the epoxide/ $\mathrm{R}-\mathrm{O}^{-}$reaction. A generalized kinetics model was developed and used to predict the conversion of epoxide groups using a wide range of imidazole and BPA concentrations, and cure temperature. (C) 1999 John Wiley \& Sons, Inc. J Polym Sci A: Polym Chem 37: 3233-3242, 1999
\end{abstract}

Keywords: Epoxy; imidazole; cure kinetics; cure mechanisms

\section{INTRODUCTION}

In recent years there has been a great increase in the number of applications of epoxy-phenol resins, especially in the electronics industry as encapsulating and packaging materials. ${ }^{1-3}$ Nowadays the chip sizes have become larger, while the dimensions of devices inside the chip have become smaller and the structure of chips has become more delicate. Molding compounds need to have much more stringent properties like higher thermal resistance, higher moisture resistance, lower thermal expansion coefficient, and lower modulus. ${ }^{4}$ Encapsulants formulated out of epoxy-phenol resins are transfer-molded to form the protective shell outside integrated circuits. During the polymerization, the molecular weight increases and the crosslinked structure builds up, which governs the rheological and mechanical properties of the cured resins. Thus it was particularly important to understand thoroughly the cure ki-

Correspondence to: W. Y. Chiu

Journal of Polymer Science: Part A: Polymer Chemistry, Vol. 37, 3233-3242 (1999) ๑) 1999 John Wiley \& Sons, Inc. netics because of its effect on stress distribution in the IC packaging during processing. There have been several existing publications, reviewed as below.

Shechter and Wynstra ${ }^{5}$ were the first to examine the uncatalyzed epoxy-phenol reaction. They found that the reaction is sluggish at $200^{\circ} \mathrm{C}$ and was found to proceed at reasonable rate only at higher temperatures. In the meanwhile epoxide disappeared at a faster rate than phenol, with about $60 \%$ of the reaction being between epoxide and phenol, and the remaining $40 \%$ being between epoxide and the secondary hydroxyl resulted from the epoxide-phenol reaction. However, this reaction procedure is too slow for highspeed integrated circuit packaging purposes, which require the reaction to be essentially completed in a few minutes at temperatures around $170^{\circ} \mathrm{C}$. Shechter and Wynstra found that some catalysts like tertiary amines or potassium hydroxide could improve the epoxy-phenol reaction selectivity and substantially lower the activation energy.

Sorokin and Shode ${ }^{6,7}$ proposed two mechanisms for creating ionic species which were poten- 
tially capable of further propagating the reaction. The acidity of the phenol used and the basicity of the tertiary amine selected determined which one of the two mechanisms dominated the propagation reactions. All Sorokin's work on the epoxyphenol reaction was carried out with a phenol/ epoxy ratio $>1$. So no side reactions were observed from his studies.

In addition to the main epoxy-phenol reaction, Gagnebien, Madec, and Marechal ${ }^{8}$ proposed three other possible mechanisms in epoxy-phenol reactions catalyzed by tertiary amines. First is epoxy homopolymerization as initiated by the free tertiary amine. Second is a branching reaction. Third is a zwitterion catalyzed branching reaction. The selectivity of reactions depended on the kind of catalyst used.

Hale and Macosko ${ }^{9}$ studied the imidazolecured epoxy-phenol reaction. They showed that the selectivity of imidazoles strongly depends on their concentration. If a low amount of imidazole is used, the reaction takes place exclusively through the addition of phenol to epoxide even if the latter is used in excess. However a larger amount of imidazole causes secondary hydroxyl groups to react with epoxide. But the reaction of secondary hydroxyl with epoxide is prevented to any significant extent as long any phenol remains in the reaction mixture. In addition, some information has been published about the use of imidazoles for catalyzing the homopolymerization of epoxide. ${ }^{10-16}$

Among the previous studies in the publications above, both detailed and quantitative reaction mechanisms have been proposed for tertiary amine catalyzed epoxy-phenol reactions. However, there could not be found any generalized kinetic mechanisms for the imidazole catalyzed epoxy-phenol reaction which can explain the cure reaction qualitatively and predict the conversion quantitatively over a wide range of reaction conditions. This is essential in order to understand the chemorheology and the structure buildup during transfer molding. The objective of this study is to examine the kinetics of imidazole cure of epoxyphenol resins at different epoxy/phenol molar ratios by using the differential scanning calorimetric (DSC) technique. ${ }^{17,18}$ Based on the previous studies described above, we combined the reaction mechanisms for tertiary amine catalysis and for imidazole catalysis and proposed a generalized kinetics model which can quantitatively predict the conversion of epoxide for a wide range of
DGEBA/BPA/imidazole molar ratios and cure temperatures. By use of the numerical skills, all the reaction rate constants were properly tuned and discussed in this paper.

\section{EXPERIMENTAL}

\section{Materials}

The epoxy resin (DER332), a nearly pure form of the diglycidyl ether of bisphenol A(DGEBA), was supplied by the Dow Chemical Company. The epoxide equivalent weight (EEW) of DER332, determined by titration, was $174 \mathrm{~g} /$ mol-epoxide. The difunctional phenol, bisphenol A (BPA) with a purity $>99 \%$, was obtained from the Tokyo Chemical Industry Company. The imidazole, 2-ethyl-4-methyl-imidazole (2,4EMI) with a purity $>99 \%$, was obtained from Acros Organics. All materials were stored in a desiccator and used as received without further purification.

\section{Sample Preparation}

Different molar ratios of BPA/epoxide and $2,4 \mathrm{EMI}$ were dissolved separately in spectrometric grade acetone. Both of the solutions were added, mixed well by rigorous stirring, and the acetone was evaporated under vacuum at $30^{\circ} \mathrm{C}$ for 10 minutes. The resultant mixture was immersed in ice water immediately to minimize further cure reaction before kinetics studies. The prepared samples were surveyed from room temperature to $320^{\circ} \mathrm{C}$ by thermogravimetric analysis (TGA). The results of TGA showed that the total weight loss caused by residual acetone loss and thermal degradation of resultant mixture is less than $1 \%$.

\section{Differential Scanning Calorimeter (DSC) Analysis}

Both dynamic and isothermal differential scanning calorimetry were performed by using a TA Instruments (TA-2010) DSC under nitrogen atmosphere. The DSC enthalpy and temperature scale were calibrated using a high purity indium sample. Dynamic scans from $2.5^{\circ} \mathrm{C}$ to $20^{\circ} \mathrm{C} / \mathrm{min}$ over a temperature range of $25-320^{\circ} \mathrm{C}$ were used to cure the $2,4 \mathrm{EMI} / \mathrm{BPA} /$ epoxide samples. Isothermal studies were also performed at four fixed temperatures $\left(90^{\circ} \mathrm{C}, 95^{\circ} \mathrm{C}, 100^{\circ} \mathrm{C}, 110^{\circ} \mathrm{C}\right)$, holding for various periods of time. Both dynamic and 
isothermal samples were quenched to $-40^{\circ} \mathrm{C}$ and scanned up to $300^{\circ} \mathrm{C}$ at a heating rate $20^{\circ} \mathrm{C} / \mathrm{min}$ to detect the residual heat of reaction and glass transition temperature $\left(T_{g}\right)$.

\section{RESULTS AND DISCUSSION}

\section{Reaction Mechanisms}

Based on the previous studies of Gagnebien, Madec, and Marechal, ${ }^{8}$ Heise, ${ }^{19}$ and Biernath and Soane, ${ }^{20}$ our proposed curing mechanisms are shown in Figure 1. There are two initiation mechanisms. The first one starts with adduct ion of the pyridine-type nitrogen with the epoxy $(1.1,1.2)$. The second results from the ionic nature of the 2,4EMI-phenol interaction $(1.4,1.5)$. The following propagation steps consist of three main reaction mechanisms, the epoxide/phenol reaction (1.6), the acid-base reaction $(1.3,1.7)$, and the epoxide $/ \mathrm{R}^{-} \mathrm{O}^{-}$reaction $(1.8,1.9)$.

\section{DSC Analysis}

The reaction kinetics were studied using DSC because the amount of heat evolved during reaction is related to the number of reacting epoxide molecules. ${ }^{18}$ Both dynamic and isothermal traces were employed to analyze the DGEBA/BPA/ $2,4 \mathrm{EMI}$ reaction.

\section{Dynamic Studies}

The DSC dynamic traces for 100/6 molar ratio of DGEBA and 2,4EMI cured with different concentrations of BPA are illustrated in Figure 2. For DGEBA cured with $100 \%$ molar ratio of BPA, there is enough phenol to consume all epoxides to give linear aromatic ether chains with secondary hydroxyl groups. The DSC thermogram exhibited a single exotherm as showed in Figure 2. As the BPA concentration is lowered, some epoxide groups are unreacted after the initial eoxide/phenol reaction. These free epoxides could react with $\mathrm{R}_{-} \mathrm{O}^{-}$to form aliphatic ethers. Consequently DGEBA cured with $60 \%$ molar ratio of BPA exhibits two exothermic peaks. As the BPA concentrations is lowered below $40 \%$ molar ratio, the epoxide/phenol reaction appears as a low temperature exotherm shoulder and the epoxide/ $\mathrm{R}^{-} \mathrm{O}^{-}$ reaction as a large exothermic peak. This is characterized by a high heat flow corresponding to a higher reaction rate.
The dynamic DSC scan was used to analyze curing reactions that exhibit several exotherms. ${ }^{17}$ The reaction heat was determined for five different heating rates varying from $2.5^{\circ} \mathrm{C} / \mathrm{min}$ to $20^{\circ} \mathrm{C} /$ min over a temperature range of $25^{\circ} \mathrm{C}-300^{\circ} \mathrm{C}$. The measured results were plotted versus different heating rates. The best fitting line was obtained by linear regression. The total heat of reaction, $\Delta \mathrm{H}_{\text {tot }}$, was obtained by extrapolating the best fitting line to zero heating rate. Total heat of reaction obtained this way is summarized in Table I. As can be seen from the table, the heat of reaction for a range of DGEBA/BPA/2,4EMI compositions varied between 76 and $88 \mathrm{~kJ} / \mathrm{mol}$-epoxide. These values agreed very well with those obtained by Enikolopiyan ${ }^{21}$ and Hale. ${ }^{22}$ As shown in Table I, the total heats of reaction do not vary significantly with BPA concentration, indicating that the heats of reaction for the two etherification reactions are almost the same. Hence thermal conversion could be related directly to the conversion of epoxide group. ${ }^{18}$

Both dynamic and isothermal samples were scanned after the initial curing to $300^{\circ} \mathrm{C}$ at $20^{\circ} \mathrm{C} /$ min to determine $T_{g}$. $T_{g}$ of the cured resins is a strong function of BPA concentration as shown in Table I. As the BPA concentration is lowered, more epoxide groups become available for the chain branching, epoxide/ $\mathrm{R}_{-} \mathrm{O}^{-}$reaction, which increases the crosslinking density of the resultant resins and results in a higher $T_{g}$. For $100 \%$ molar ratio of $\mathrm{BPA}$, the $T_{g}$ is between 69 and $75^{\circ} \mathrm{C}$, while for $25 \%$ molar ratio of $\mathrm{BPA}$, the $T_{g}$ value is around $140^{\circ} \mathrm{C}$.

\section{Isothermal Studies}

On the basis of the above dynamic DSC studies, isothermal DSC scans were performed at four different temperatures $\left(90,95,100\right.$, and $\left.110^{\circ} \mathrm{C}\right)$. The isothermal DSC thermograms for 100/6 molar ratio of DGEBA and 2,4EMI cured with different concentrations of BPA are showed in Figure 3. There are two distinct exothermic peaks. The first one corresponds to the epoxide/phenol reaction while the second can be attributed to the epoxide/ $/ \mathrm{R}^{-} \mathrm{O}^{-}$reaction. Increasing the BPA concentration delays the occurrence of the epoxide/ $\mathrm{R}-\mathrm{O}^{-}$reaction since the required time to react all the phenol groups is increased. And the area under the second peak decreases because fewer epoxide molecules are left after the epoxide/phenol reaction. 
I. Initiated by $1: 1$ adduct $\& 2: 1$ adduct

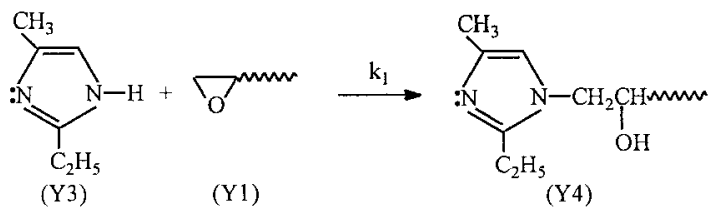

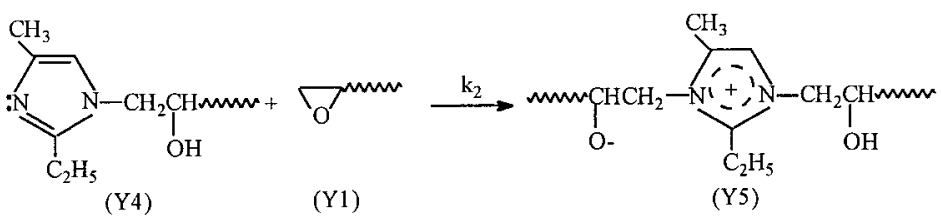

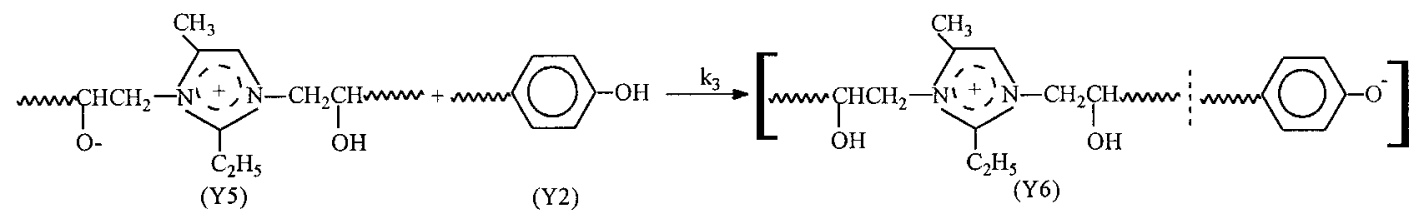

(Y2)

II Initiated by 2,4 EMI \& BPA Complex

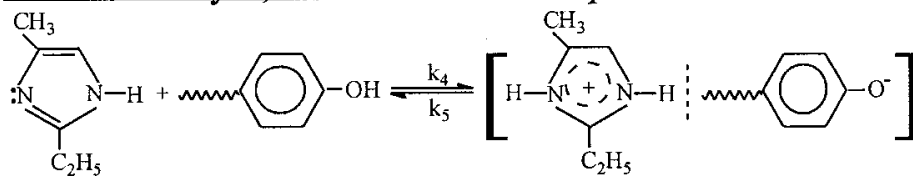

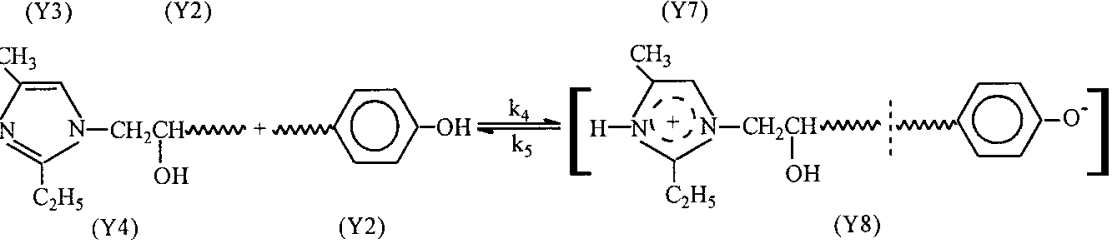

\section{Propagation}

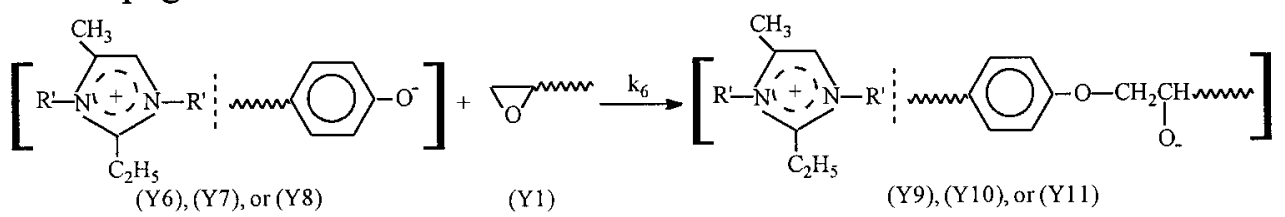

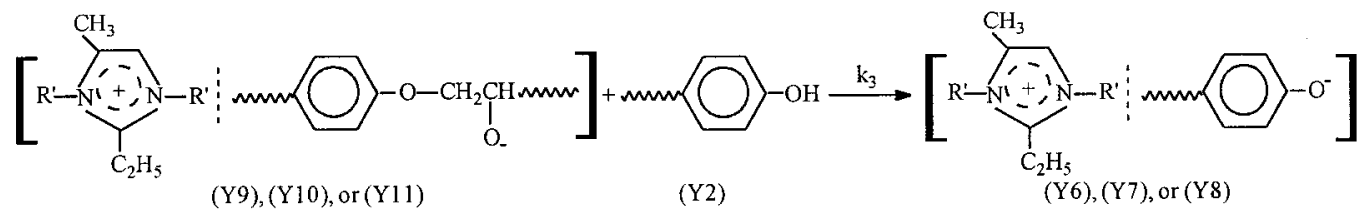<smiles>C[C@@H](O)COc1ccc([18F])cc1</smiles>

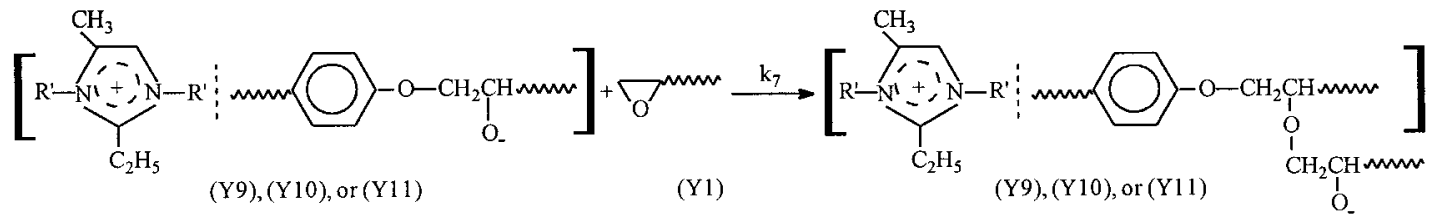

Figure 1. Reaction mechanisms proposed for DGEBA cured with 2,4EMI and BPA. 


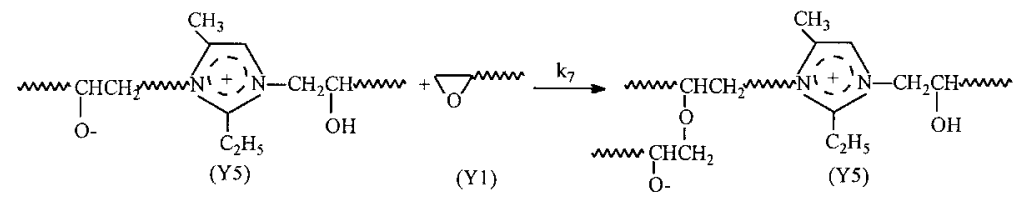

where $\stackrel{\mathrm{R}^{\prime}: \mathrm{H} \text { or } \mathrm{CH}_{2} \mathrm{CH} \text { mmm }}{\mathrm{OH}}$

Figure 1. (Continued from previous page)

The thermal conversion during the isothermal reaction can be expressed as:

$$
X(t)=\Delta H_{\text {to to }} / \Delta H_{\text {total }}
$$

where $\mathrm{X}(\mathrm{t})$ is the thermal conversion at time $\mathrm{t}$, $\Delta \mathrm{H}_{\text {total }}$ is the total heat of reaction determined from dynamic DSC studies, and $\Delta \mathrm{H}_{\mathrm{t} 0}$ to $\mathrm{t}$ is the heat of reaction from initial time $t_{0}$ to time $t$ during the isothermal reaction.

Figure 4 shows the influence of BPA concentrations on isothermal reactions. There is an obvious transition when BPA molar ratio is less than $40 \%$ as shown in Figure 4. The lower time interval slope is dominated by the value of the rate constant of the epoxide/phenol reaction and the higher time interval slope represents that of the epoxide/ $\mathrm{R}-\mathrm{O}^{-}$reaction. If the BPA molar ratio is higher than $80 \%$, most of the epoxide groups are

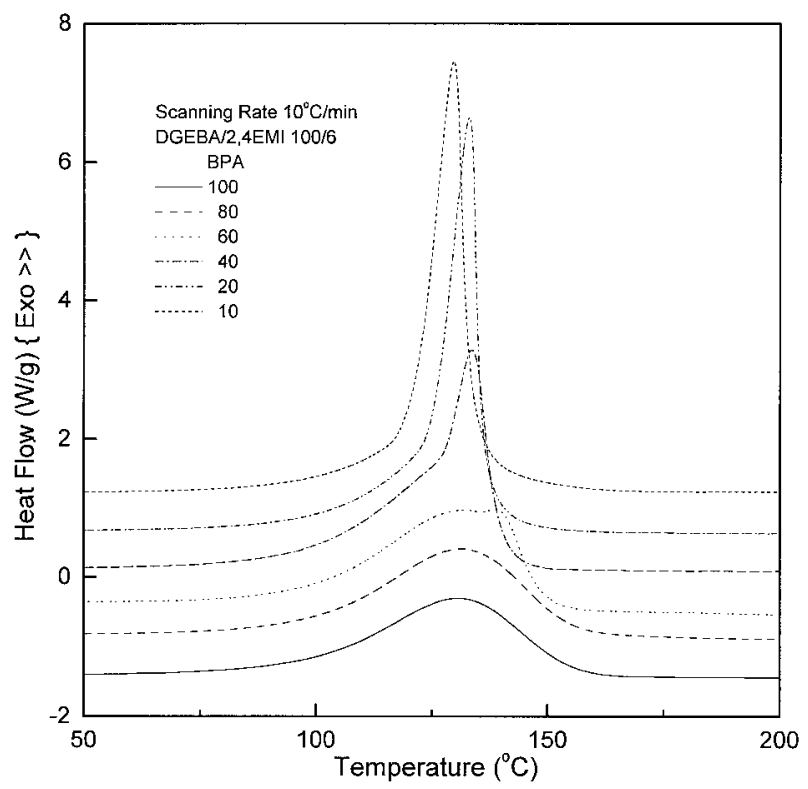

Figure 2. DSC dynamic traces at $10^{\circ} \mathrm{C} / \mathrm{min}$ for the cure of DGEBA with $6 \%$ molar ratio of $2,4 \mathrm{EMI}$ and various molar ratios of BPA. consumed by the epoxide/phenol reaction, so no transition can be expected up to $70 \%$ conversion (i.e., $\ln (1-\mathrm{X})=-1.2)$. The rate of the epoxide/ phenol reaction is also accelerated if the BPA concentration is increased.

The influence of 2,4EMI concentrations are shown in Figure 5. As the 2,4EMI concentration is increased, both epoxide/phenol and epoxide/R- $\mathrm{O}^{-}$ reaction rates increase because more active ionic centers are formed which take part in the subsequent propagation reactions.

Increasing isothermal temperature accelerates both the epoxide/phenol and the epoxide/ $\mathrm{R}^{-} \mathrm{O}^{-}$reaction. These results are shown in Figure 6.

\section{Kinetics Modeling and Theoretical Approaches}

The reaction mechanisms shown in Figure 1 can be expressed as the following mathematical scheme: (where " $y_{1}$ " species are identified in Figure 1)

$$
\begin{array}{r}
\frac{d y_{1}}{d t}=-k_{1} y_{1} y_{3}-k_{2} y_{1} y_{4}-k_{6} y_{1}\left(y_{6}+y_{7}+y_{8}\right) \\
-k_{7} y_{1}\left(y_{5}+y_{9}+y_{10}+y_{11}\right)
\end{array}
$$

$$
\begin{array}{r}
\frac{d y_{2}}{d t}=-k_{3} y_{2} y_{5}-k_{4} y_{2}\left(y_{3}+y_{4}\right)+k_{5}\left(y_{7}+y_{8}\right) \\
-k_{3} y_{2}\left(y_{9}+y_{10}+y_{11}\right)
\end{array}
$$$$
\frac{d y_{3}}{d t}=-k_{1} y_{1} y_{3}-k_{4} y_{2} y_{3}+k_{5} y_{7}
$$

$\frac{d y_{4}}{d t}=k_{1} y_{1} y_{3}-k_{2} y_{1} y_{4}-k_{4} y_{2} y_{4}+k_{5} y_{8}$

$\frac{d y_{5}}{d t}=k_{2} y_{1} y_{4}-k_{3} y_{2} y_{5}$ 
Table I. The Heat of Reaction $\left(\Delta H_{\text {tot }}\right)$ and Glass Transition Temperature $\left(T_{g}\right)$ for Different DGEBA/BPA/2,4EMI Resin Compositions (where DGEBA: 100)

\begin{tabular}{|c|c|c|c|c|c|c|}
\hline $2,4 \mathrm{EMI}$ & \multicolumn{2}{|l|}{2} & \multicolumn{2}{|l|}{4} & \multicolumn{2}{|l|}{6} \\
\hline BPA & $\begin{array}{c}\Delta H_{\text {tot }} \\
(\mathrm{KJ} / \mathrm{mole} \text {-epoxide })\end{array}$ & $T_{g}\left({ }^{\circ} \mathrm{C}\right)$ & $\begin{array}{c}\Delta H_{\text {tot }} \\
(\mathrm{KJ} / \mathrm{mole} \text {-epoxide })\end{array}$ & $T_{g}\left({ }^{\circ} \mathrm{C}\right)$ & $\begin{array}{c}\Delta H_{\text {tot }} \\
(\mathrm{KJ} / \text { mole-epoxide })\end{array}$ & $T_{g}\left({ }^{\circ} \mathrm{C}\right)$ \\
\hline 100 & 76.7866 & 74.8 & 78.7094 & 72.2 & 77.2882 & 69.7 \\
\hline 80 & 78.9602 & 85.0 & 79.1692 & 79.8 & 78.5840 & 76.6 \\
\hline 60 & 82.0116 & 94.9 & 80.3814 & 91.2 & 78.9184 & 83.7 \\
\hline 40 & 80.5068 & 111.9 & 81.7608 & 106.0 & 79.1274 & 96.7 \\
\hline 20 & 81.7608 & 132.6 & 82.1370 & 129.9 & 82.2624 & 115.5 \\
\hline 10 & 85.6064 & 132.3 & 87.6128 & 131.9 & 84.5614 & 125.7 \\
\hline \multicolumn{3}{|c|}{$\frac{d y_{6}}{d t}=k_{3} y_{2}\left(y_{5}+y_{9}\right)-k_{6} y_{1} y_{6}$} & (7) & \multicolumn{2}{|c|}{$\frac{d y_{10}}{d t}=k_{6} y_{1} y_{7}-k_{3} y_{2} y_{10}$} & (11) \\
\hline$\frac{d y_{7}}{d t}=$ & $y_{3}-k_{5} y_{7}-k_{6} y_{1} y$ & $y_{2} y_{10}$ & (8) & \multicolumn{2}{|l|}{$d y_{11}$} & (12) \\
\hline
\end{tabular}

$\frac{d y_{8}}{d t}=k_{4} y_{2} y_{4}-k_{5} y_{8}-k_{6} y_{1} y_{8}+k_{3} y_{2} y_{11}$

$\frac{d y_{9}}{d t}=k_{6} y_{1} y_{6}-k_{3} y_{2} y_{9}$

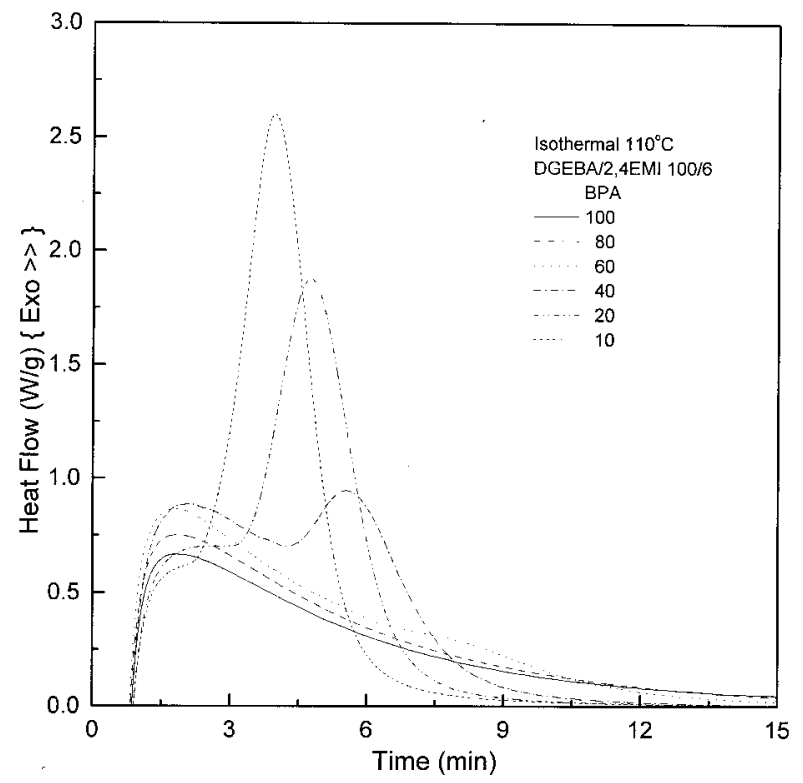

Figure 3. DSC isothermal thermograms for DGEBA cured with $6 \%$ molar ratio of $2,4 \mathrm{EMI}$ and vaarious molar ratios of $\mathrm{BPA}$ at $110^{\circ} \mathrm{C}$.
The adaptive step-size of Cash-Karp RungeKutta method ${ }^{23}$ was selected for the numerical procedure to solve ordinary differential eqs (2) to (13), programmed in Fortran language, and then executed by a Pentium II-233 microprocessor. All the parameters used in calculation were listed in

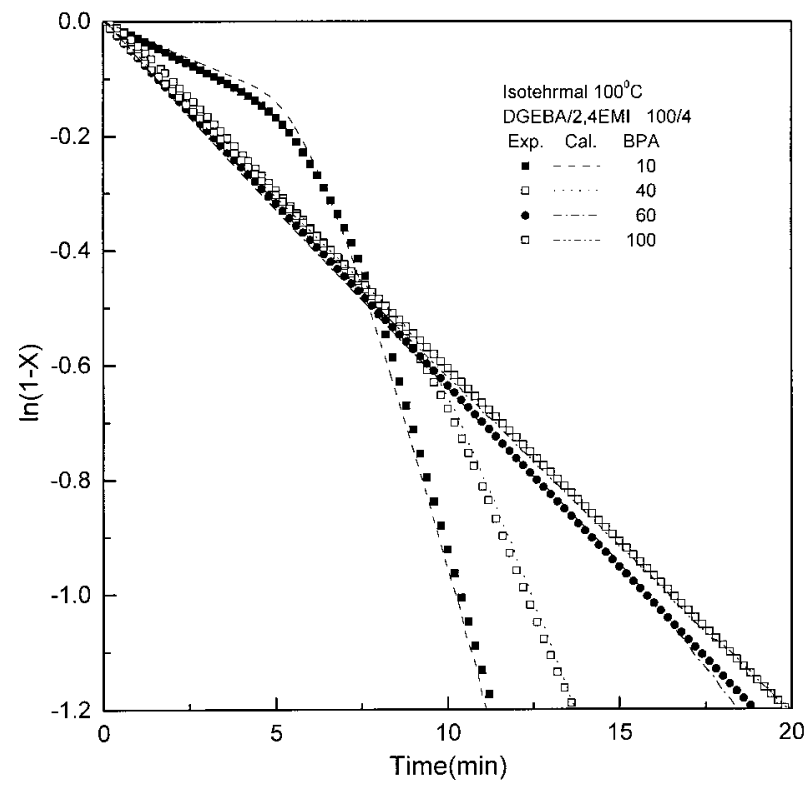

Figure 4. Comparison of the model results with the experimental epoxide conversion curves for DGEBA cured with $4 \%$ molar ratio of $2,4 \mathrm{EMI}$ and different molar ratios of $\mathrm{BPA}$ at $100^{\circ} \mathrm{C}$. 


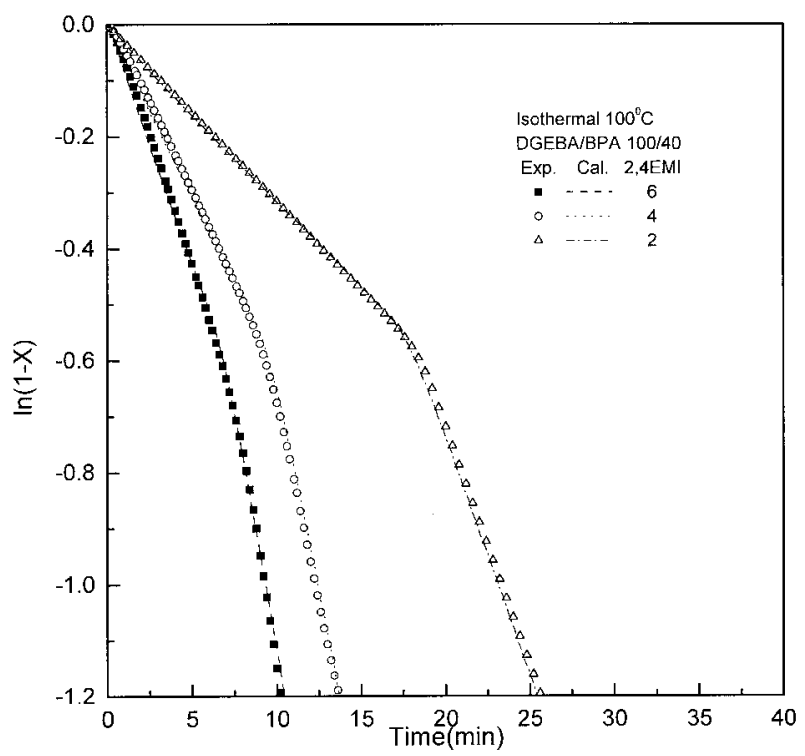

Figure 5. Comparison of the model results with the experimental epoxide conversion curves for DGEBA cured with $40 \%$ molar ratio of BPA and different molar ratios of $2,4 \mathrm{EMI}$ at $100^{\circ} \mathrm{C}$.

Table II. The concentration profiles of $\mathrm{y}_{1}$ to $\mathrm{y}_{11}$ versus time can be simultaneously calculated. Then the conversion of epoxide (X) can be calculated as $X=\frac{1-y_{1}(t)}{y_{1}^{0}}$ where $\mathrm{y}_{1}^{0}$ is the initial concentration of epoxide and $y_{1}(t)$ is the concentration of epoxide at time $t$. The comparisons between theoretical and empirical results are plotted in Figures 4 to 6 . With proper tuning parameters, all experimental data could be simulated by the proposed kinetics model very well.

Reaction rate constants $\mathrm{k}_{1}$ and $\mathrm{k}_{2}$ represent the adduct formation of pyridine-type nitrogen with epoxide group and were referred from the previous studies of Heise. ${ }^{19}$

The constant $k_{3}$ represents the rate constant of an acid-base reaction between an alkoxide ion and a phenolic hydroxyl group to create a secondary hydroxyl group and a phenoxide ion as shown in Figure 1. In the presence of unreacted phenolic hydroxyls, the anionic homo-polymerization, i.e. the epoxide $/ \mathrm{R}^{-} \mathrm{O}^{-}$reaction, is suppressed since the alkoxide ion is a stronger base than phenoxide ion. It means that the rate of acid-base reaction is higher than the rates of the etherification reaction; therefore, the epoxide/phenol and the epoxide/ $\mathrm{R}-\mathrm{O}^{-}$reaction occur separately. The optimum value of $k_{3}$ was found from the conversion rate curves as showed in Figure 7. The slope of the curve between point $\mathrm{A}$ and $\mathrm{B}$ depended on the value of $k_{3}$ selected. The value also influenced the curvature at point $\mathrm{B}$. The optimum curve fitting results of $k_{3}$ are listed in Table II. They are a strong function of reaction temperature but are insensitive to concentration changes of $2,4 \mathrm{EMI}$ or BPA. The activation energy for $k_{3}$ is only ca. 39 $\mathrm{kJ} / \mathrm{mol}$, which is less than that of the etherfication reaction. ${ }^{19}$

The reaction rate constant $\mathrm{k}_{4}$ was determined from the initial slope change as shown in Figure 7. The rate constant $k_{4}$ represents the forward part of an equilibrium reaction which results in complexes between the pyridine-type nitrogen of $2,4 \mathrm{EMI}$ and the phenolic hydroxyl of BPA. Since the energy gap for the complex formation is very small, its activation energy is less than that of other reactions in this system. In our calculations, the value of $\mathrm{k}_{4}$ was set as $5 \times 10^{-2}(\mathrm{~L} / \mathrm{mol}-\mathrm{sec})$ and assumed to be insensitive to the concentration changes of 2,4EMI or BPA, and reaction temperatures.

The reaction rate constant $k_{5}$ represents the backward part of the previously mentioned equilibrium. Its value influences the whole reaction time period, especially in the final reaction stage. When species Y2, Y3, and Y4 (Fig. 1) are consumed to form active phenoxide ions, their concentrations decrease. The backward reaction gradually becomes important since more phenox-

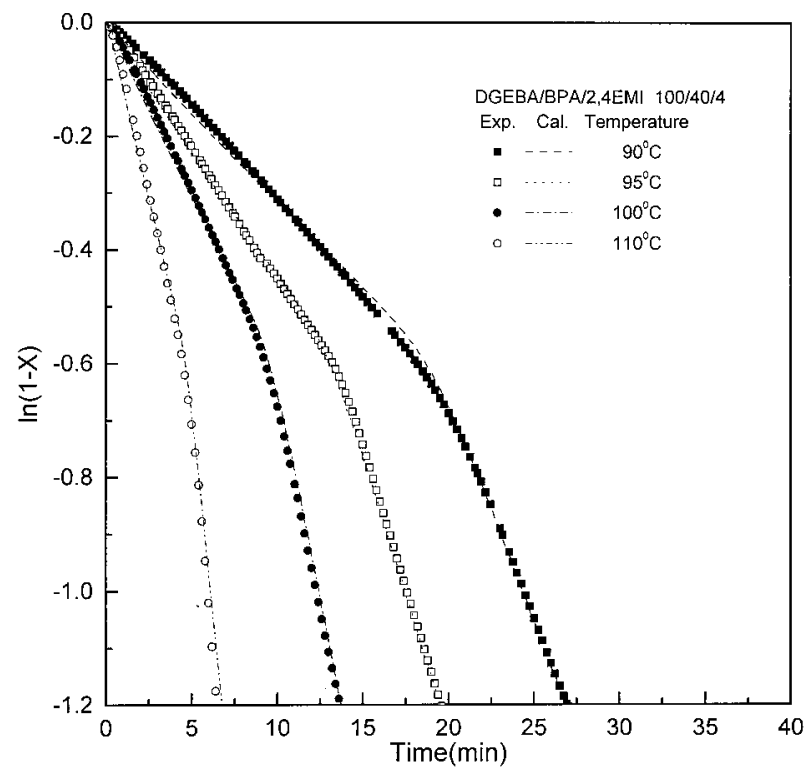

Figure 6. Comparison of the model results with the experimental epoxide conversion curves for DGEBA cured with $40 \%$ molar ratio of BPA and $4 \%$ molar ratio of $2,4 \mathrm{EMI}$ at different isothermal temperatures. 
Table II. Reaction Rate Constants Used in Calculation and Activation Energies Determined from Isothermal DSC Result

\begin{tabular}{|c|c|c|c|c|c|c|}
\hline \multicolumn{3}{|c|}{$k_{1}$ and $k_{2}(\mathrm{~L} / \mathrm{mol}-\mathrm{sec})^{22}$} & & \multicolumn{3}{|c|}{$k_{3}(\mathrm{~L} / \mathrm{mol}-\mathrm{sec})$} \\
\hline \multicolumn{2}{|l|}{$\operatorname{Ln}(\mathrm{A})$} & \multicolumn{2}{|l|}{$E_{a}(\mathrm{KJ} / \mathrm{mol})$} & $\operatorname{Ln}(\mathrm{A})$ & \multicolumn{2}{|c|}{$E_{a}(\mathrm{KJ} / \mathrm{mol})$} \\
\hline 18.33 & & 74 & & 13.52 & 38. & \\
\hline $\begin{array}{c}\text { Molar Ratio } \\
\text { DGEBA/BPA/2,4EMI }\end{array}$ & $\operatorname{Ln}(\mathrm{A})$ & $\frac{k_{6}(\mathrm{~L} / \mathrm{mol}-\mathrm{sec})}{E a(\mathrm{KJ} / \mathrm{mol})}$ & $R$ & $\operatorname{Ln}(\mathrm{A})$ & $\frac{k_{7}(\mathrm{~L} / \mathrm{mol}-\mathrm{sec})}{E a(\mathrm{KJ} / \mathrm{mol})}$ & $R$ \\
\hline $100 / 10 / 6$ & 28.26 & 108.78 & -0.995 & 20.40 & 74.58 & -0.997 \\
\hline $100 / 10 / 4$ & 29.91 & 113.05 & -0.999 & 17.07 & 64.70 & -0.995 \\
\hline $100 / 10 / 2$ & 25.26 & 97.61 & -0.999 & 17.98 & 67.73 & -0.996 \\
\hline $100 / 20 / 6$ & 20.30 & 81.94 & -0.998 & 19.37 & 72.40 & -0.999 \\
\hline $100 / 20 / 4$ & 23.47 & 91.05 & -0.997 & 16.34 & 62.89 & -0.999 \\
\hline $100 / 20 / 2$ & 21.99 & 85.57 & -0.998 & 15.75 & 60.95 & -0.999 \\
\hline $100 / 40 / 6$ & 20.40 & 79.81 & -0.998 & 21.46 & 80.07 & -0.997 \\
\hline $100 / 40 / 4$ & 20.62 & 80.18 & -1.000 & 20.73 & 77.36 & -0.992 \\
\hline $100 / 40 / 2$ & 20.45 & 79.45 & -0.999 & 16.15 & 62.81 & -0.994 \\
\hline $100 / 60 / 6$ & 20.06 & 78.01 & -1.000 & 21.15 & 80.96 & -0.999 \\
\hline $100 / 60 / 4$ & 20.43 & 79.04 & -0.999 & 23.21 & 86.81 & -0.998 \\
\hline $100 / 60 / 2$ & 20.00 & 77.59 & -0.999 & 21.82 & 81.40 & -0.998 \\
\hline $100 / 80 / 6$ & 21.35 & 81.67 & -0.998 & 21.35 & 81.67 & -0.998 \\
\hline $100 / 80 / 4$ & 21.35 & 81.42 & -0.998 & 21.35 & 81.42 & -0.998 \\
\hline $100 / 80 / 2$ & 20.29 & 78.17 & -0.997 & 20.29 & 78.17 & -0.997 \\
\hline $100 / 100 / 6$ & 20.68 & 79.34 & -0.998 & 20.68 & 79.34 & -0.998 \\
\hline $100 / 100 / 4$ & 20.69 & 79.30 & -0.997 & 20.69 & 79.30 & -0.997 \\
\hline $100 / 100 / 2$ & 20.72 & 79.29 & -0.999 & 20.72 & 79.29 & -0.999 \\
\hline
\end{tabular}

ide anions of species $\mathrm{Y} 7$ and $\mathrm{Y} 8$ convert back into $\mathrm{Y} 2$, Y3, and Y4. Therefore, the apparent reaction rate gradually slows down. The reverse reaction would cause a serious deviation from experimental results unless the value of $k_{5}$ is small enough. In the model calculation, $\mathrm{k}_{5}$ was selected as $10^{-7}$ $(1 / \mathrm{sec})$ and assumed to be insensitive to reaction temperature and concentration changes of 2,4EMI and BPA.

The optimum reaction rate constant $\mathrm{k}_{6}$ and its activation energy is listed in Table II. The values of $\mathrm{k}_{6}$ decide the occurrence of the second peak and the height of the plateau between point A and B as shown in Figure 7. And the results indicate that the rate constant $\mathrm{k}_{6}$ is a strong function of reaction temperature, and 2,4EMI and BPA concentrations. Sorokin's ${ }^{6,7}$ studies showed that the degree of ionization of the binary complex is directly proportional to the acidity of phenol and the basicity of the pyridine-type nitrogen in $2,4 \mathrm{EMI}$. The degree of ionization of binary complexes would dominate the subsequent propagation rate constant $\mathrm{k}_{6}$. As the BPA concentration is increased and that of 2,4EMI is decreased, the

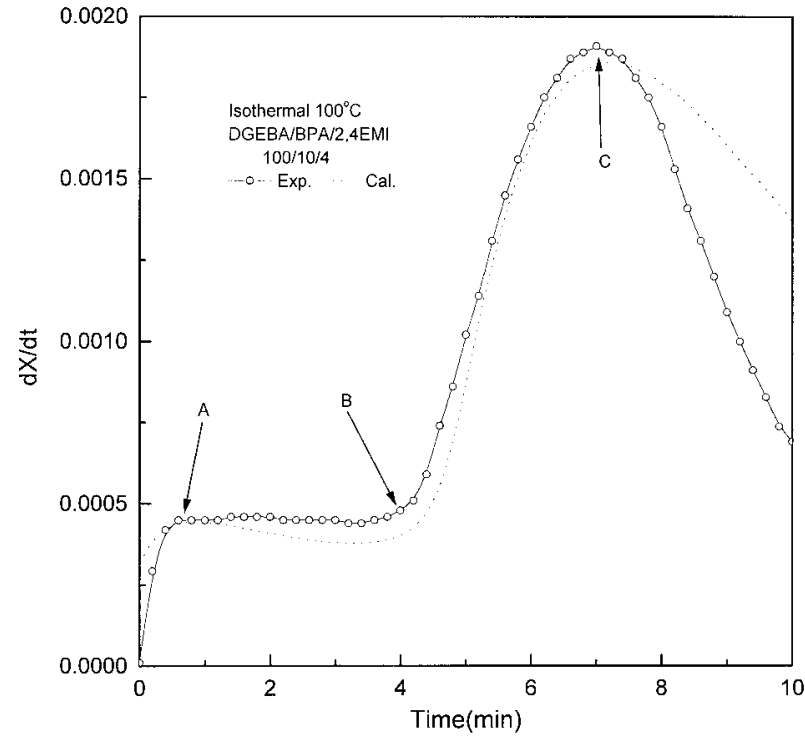

Figure 7. Comparison of the model results with the experimental epoxide conversion rate curve for DGEBA cured with $4 \%$ molar ratio of $2,4 \mathrm{EMI}$ and $10 \%$ molar ratio of $\mathrm{BPA}$ at $100^{\circ} \mathrm{C}$. 


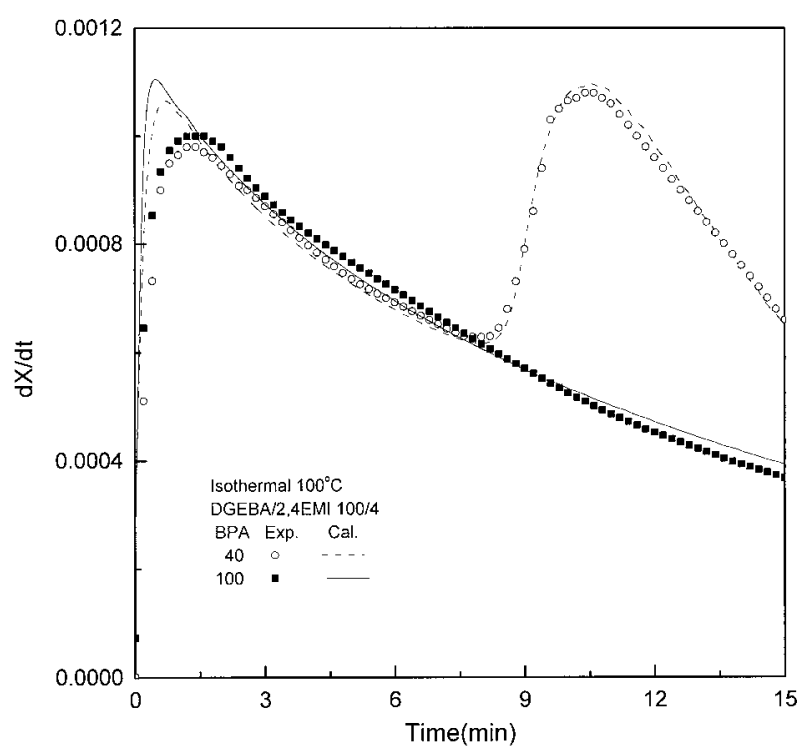

Figure 8. Comparison of the model results with the experimental epoxide conversion rate curvee for DGEBA cured with $4 \%$ molar ratio of $2,4 \mathrm{EMI}$ and $40 \%$, $100 \%$ molar ratio of $\mathrm{BPA}$ at $100^{\circ} \mathrm{C}$.

polarity of the reaction system is raised and consequently $\mathrm{k}_{6}$ becomes larger. The activation energies of rate constant $\mathrm{k}_{6}$ are between 78 and 109 $\mathrm{kJ} / \mathrm{mol}$. This finding agrees with the studies of Heise. ${ }^{19}$

Table II lists the most suitable reaction rate constant $\mathrm{k}_{7}$. The slope of the conversion rate curve during the time period between point $\mathrm{B}$ and $\mathrm{C}$ in Figure 7 determines the optimum value of $\mathrm{k}_{7}$. It is a strong function of reaction temperature and BPA concentration. Since increasing the BPA concentration delays the initiation of epoxide/ $\mathrm{R}-\mathrm{O}^{-}$reaction, the average molecular weight per ionic propagating chain is increased. The steric obstacle becomes more serious if the BPA concentration is raised; therefore, the reaction rate constant is decreased proportional to the BPA concentration increase. The activation energies of reaction rate constant $\mathrm{k}_{7}$ were between 60 and 82 $\mathrm{kJ} / \mathrm{mol}$, which is a little less than that of $\mathrm{k}_{6}$. As the BPA molar ratio increased higher than $80 \%$, no obvious second exotherm peak was seen from the isothermal DSC traces. So the tuning of $\mathrm{k}_{7}$ became difficult and insensitive. In Table II, $\mathrm{k}_{7}$ was assumed to be the same as $\mathrm{k}_{6}$ in numerical calculations if the BPA molar ratio was higher than $80 \%$.

Figures 7 and 8 show the comparison of conversion rate between model calculations and experimental results from isothermal DSC traces at different BPA concentrations. There is a little deviation between experimental and theoretical curves in the initial period of time. It might be caused by the instrument's measuring error, since a time period is needed for the thermal controller of the DSC to reach the desired setpoint temperature.

\section{CONCLUSIONS}

The reaction kinetics of imidazole cured epoxidephenol resins were studied both by dynamic and isothermal DSC. There were two initiation mechanisms. The first was from adduct reactions of pyridine-type nitrogen. The second stemmed from the ionic complexes of $2,4 \mathrm{EMI} / \mathrm{BPA}$ interaction. A generalized kinetic model was proposed and all parameters needed for computation were properly tuned from the conversion rate curves. The rate constant of the acid/base reaction was higher than that of the etherification, since the alkoxide ion is a stronger basse than the phenoxide ion. The optimum value of $\mathrm{k}_{3}$ from parameter tuning (see text) agrees with this principle very well. And the activation energy of the rate constant $\mathrm{k}_{3}$ was $39 \mathrm{~kJ} / \mathrm{mol}$, which is less than that of the etherification reaction. The rate constant $\mathrm{k}_{6}$ is found to be a strong function of the molar ratio of BPA and $2,4 \mathrm{EMI}$. The reason is that the degree of ionization of binary complexes (Y6, Y7, and Y8) was proportional to the acidity of the phenol and the basicity of the pyridine-type nitrogen in 2,4EMI. With proper tuning parameters, our kinetic model can predict the conversion of epoxide groups for a wide range of imidazole and BPA concentrations, and cure temperatures.

\section{REFERENCES AND NOTES}

1. Kinjo, N.; Ogata, M.; Nishi, K; Kaneda, A. Adv Polym Sci 1989, 88, 1.

2. Soane, D. S.; Martynenko, Z. Polymers in Microelectronics; Elsevier: New York, 1989.

3. Wong, C. P. Polymers for Electronic and Photonic Applications; Academic Press: New York, 1993.

4. Bair, H. E.; Boyle, D. J.; Ryan, J. T.; Taylor, C. R.; Tighe, S. C. Polym Eng Sci 1990, 30(10), 609.

5. Shechter, L.; Wynstra, J. Ind Eng Chem 1956, 48(1), 86.

6. Sorokin, M. F.; Shode, L. G. Zh Org Khim 1966, 2, 1447.

7. Sorokin, M. F.; Shode, L. G. Zh Org Khim 1966, 2, 1463. 
8. Gagnebien, D.; Madec, P. J.; Marechal, E. Eur Polym J 1985, 21(3), 273.

9. Hale, A.; Macosko, C. W. J Appl Polym Sci 1989, 38, 1253.

10. Farkas, A.; Strohm, P. F. J Appl Polym Sci 1968, $12,159$.

11. Alvey, F. B. J Appl Polym Sci 1969, 13, 1473.

12. Dearlove, T. J. J Appl Polym Sci 1970, 14, 1615.

13. Son, P. N.; Weber, C. D. J Appl Polym Sci 1973, 17, 2415.

14. William, F. R.; Romanchick, A.; Joullie, M. M. J Polym Sci Polym Chem Ed 1983, 21, 1475.

15. Heise, M. S.; Martin, G. C. Macromolecules 1989, 22, 99.

16. Heise, M. S.; Martin, G. C. J Appl Polym Sci 1990,
$39,721$.

17. Turi, E. A. Thermal Characterization of Polymeric Materials; Academic Press: New York, 1981.

18. Barton, J. M. Adv Polym Sci 1985, 72, 112.

19. Heise, M. S. Ph.D. Dissertation, Syracuse University, USA, 1989.

20. Biernath, R. W.; Soane, D. S. Contemporary Topics in Polymer Science, Vol.7; Plenum Press: New York, 1992; 103.

21. Enikolopiyan, N. S. Pure Appl Chem 1976, 48, 317.

22. Hale, A. Ph.D. Dissertation, University of Minnesota, USA, 1988.

23. Press, W. H.; Teukolsky, S. A.; Vetterling, W. T.; Flannery, B. P. Numerical Recipes in Fortran, 2nd Ed; Cambridge University Press: New York, 1992. 